\title{
An Empirical Assessment of Soft and Hard Classroom Management Strategies Employed by Teachers in Secondary Schools in Kingston and St. Andrew, Jamaica
}

\author{
Mark Anthony Brown ${ }^{1}$, Paul Andrew Bourne ${ }^{2 *}$ and Vincent MS Peterkin ${ }^{2}$ \\ ${ }^{1}$ Department of Educational Studies, University of the West Indies, Jamaica \\ ${ }^{2}$ Department of Education \& Leadership, Northern Caribbean University, Jamaica
}

\begin{abstract}
This study was conducted using quantitative method to evaluate the classroom management strategies employed by teachers in twenty secondary schools in Kingston and St Andrew, Jamaica. It has been a primary concern for teachers since there have been teachers in the classroom. A lack of classroom management affects both the teacher and the students. Studies show that some form of intervention makes a positive impact on teachers, students, and the whole school climate. Teachers need to personally connect with each student in the classroom in order to make students feel comfortable and welcome. Deviant behaviours in Jamaican classrooms seem to be a growing epidemic but a solution may be available through effective classroom management techniques. The purpose of this paper is to examine the extent to which effective classroom management is dependent on the teacher's soft strategies and personality, that is, his or her caring ability towards the students versus formal disciplinary strategies. The information was largely gathered using a survey of forty-five (45) questions issued to two hundred (200) teachers in twenty (20) secondary schools. An interesting finding is that although both types of strategies are used there is however a comparatively marginal practice of the soft strategies being used to that of the hard strategies. The findings revealed that there is no difference with who employed hard strategies. It was very evident that teachers are aware of what constitutes an effective classroom setting but, due to the high level of indiscipline they choose to use the strategies that will work for them best in a given situation. It may also have implications for teacher induction, retention, and development programs for staff. Controversies in classroom management strategies stem from the duel between behaviorist and social constructivist points of view. There are many aspects of classroom management for teachers to consider and think about, especially in their first few years of teaching. The most important thing for teachers to remember is the reason they chose to teach in the first place. Classroom management skills do not develop overnight; a teacher should have routines set up in the classroom and stick by those routines throughout the year. Again, take a deep breath and remember the reasons for becoming a teacher.
\end{abstract}

Keywords

Classroom management, Discipline, Soft strategies, Hard strategies, Teachers, Secondary schools

\section{Introduction}

Classroom management optimization is one strategy towards maximizing students' achievement as well as enhancing students' social competence. Boynton and Boynton [1] explained how ineffective classroom management skills can waste instructional time on a task and further interrupt learning environments. In addition to interrupting the classroom environment, if proper classroom management is not exercised, disruptive behaviour by a few students can have a negative effect on the teachers which can lead to other students joining in and can cause them to question the abilities of their teacher [2,3]. Undoubtedly, students behaviour has deteriorated to a worrying low which can either affect teachers job performance scorecard if they consistently are unable to manage students' behaviour; or will most likely results in high levels of dissatisfaction and drain on the educational system and a high turnover among teachers. For these reasons, it is important to study instructional and classroom management. In schools today, teachers are concerned about the high rate of indiscipline which confronts them on a regular basis; often

*Corresponding author: Paul Andrew Bourne, Department of Education \& Leadership, Northern Caribbean University, Mandeville, Manchester, Jamaica

Accepted: May 22, 2019

Published online: May 24, 2019

Citation: Brown MA, Bourne PA, Peterkin VMS (2019) An Empirical Assessment of Soft and Hard Classroom Management Strategies Employed by Teachers in Secondary Schools in Kingston and St. Andrew, Jamaica. Insights Anthropol 3(1):159-178 
Citation: Brown MA, Bourne PA, Peterkin VMS (2019) An Empirical Assessment of Soft and Hard Classroom Management Strategies Employed by Teachers in Secondary Schools in Kingston and St. Andrew, Jamaica. Insights Anthropol 3(1):159-178

times students are removed from the learning environment, because of such behaviour causing them to loose instructional time which may result in learning gaps $[2,4]$.

Due to societal changes over the years, schools seem to have more behavioural issues that will affect the way a teacher manages the classroom [4]. Disruptive behaviour does not only affect the students who are noncompliant with rules, but every other student in the classroom [5-7]. Teachers today must be constantly thinking of classroom management strategies and how best to use a specific strategy to deal with a particular issue in the classroom. The aim of all teachers is to ensure that they enhance the learning of all students by the strategies they choose. Research findings of Marzano [7] indicate teachers' actions in their classrooms have twice the impact of enhancing learning as do policies implemented at school that have to do with the curriculum, assessment, staffing collegiality, and community involvement. Therefore, for teachers to impact all students, they have to be able to provide a classroom that is conducive to learning. With a wide variety of classroom management strategies available to teachers, it is possible that some teachers will be using strategies that are more effective than others.

The purpose of the study is to determine whether the teachers' use of "soft" and disciplinary strategies could improve the classroom management process; in order to determine the impact that each style has on the student. For this quantitative study, four research questions were addressed to gain insight into the understanding of classroom management strategies utilized by a sample of teachers from twenty secondary schools in Kingston and St Andrew. The following are the research questions: 1) Are Jamaican teachers employing hard and soft-strategies in their classrooms? 2) Does the employment of hard and soft-strategies by teachers in their classroom differ based on socio-demographic characteristics? 3) Is there a correlation between the employment of hard and soft strategies by Jamaican teachers in their classroom? and 4) Does the employment of hard and soft-strategies by teachers in their classroom differ based on who is responsible for the employment of the strategies in the classroom?.

\section{Literature Review}

Teachers, often are impacted with classroom management problems when they cannot keep students attentive or when they do not understand students' motives and reasons for misbehavior [8]. If all students are hard-working, intrinsically motivated, active and dedicated it does not have to mean that discipline problems do not exist. As "even while working with these students, the teachers still have what can be labeled as discipline problem" [9].

The education system may, therefore, benefit from focusing more on developing teachers' soft skills than disciplinary strategies which have been the emphasis for a long time. Classroom management can be considered to be the efforts made by the teacher to oversee learning, student interaction, and behavior [including discipline] [10]. Studies of soft strategies and disciplinary strategies cannot ignore classroom management as its effectiveness is dependent of the strategy selected to suit a particular situation which time factor is also of essence to gain the best results.

\section{What are classroom management strategies?}

Classroom management refers to the teacher's ability to direct, organize, and facilitate the learning environment and student's behavior within a learning context. Curriculum and learning are influenced by how a teacher organizes and designs instruction and how he or she motivates and engages students. Several factors that influence the progressive and proactive management of a classroom's learning environment and student behavior are described in this entry [11]. Classroom management is much more than any one of these words or the sum of all these words [12]. In short, a well-managed classroom is a task-oriented, predictable environment where students know, what is expected of them, how to succeed, and where to gather information to meet the school's objectives. The definition further suggests that learners know what is expected of them and that they recognize the need for proper organization of classroom activities to ensure the smooth flow of the lessons [13].

The term classroom management can be described by five assumptions that classroom management involves. These are the understanding of learners' personal, psychological and learning needs, the establishment of positive teacher-learner and peer relationships, in meeting their psychological needs, the employment of classroom organization and group management methods, the use of teaching methods that facilitate the academic needs of individual learners and the classroom groups, the ability to employ a wide range of counseling and behavioural methods that involve learners in examining and correcting their own inappropriate behaviour. These assumptions demonstrate the skills that teachers need to acquire for establishing effective classrooms which impact students' academic achievement [14].

Classroom management is a prerequisite for achieving disciplinary objectives and safeguarding the well-being of students for whom the teaching and learning activities are centered [15]. Generally, many writers, researchers and teachers use the concept of classroom management, interchangeably with discipline, order, control motivation, punishment, or establishing a positive attitude, to overcome classroom management, which can be difficult to define and explain.

Research has found that "teachers who are highly skilled in classroom management spend more time in engaged instruction, use less exclusionary discipline and promote positive student development" [16]. They also found that many teachers do not receive the training and support needed to manage their classrooms in a way that improves academic engagement and pro-social behaviours. It has also been discovered that teachers who are more likely to use negative and punitive strategies to curb disruptive adolescent behaviour are more likely to experience poor classroom management as this corrodes teacher-student relationships and can add to the failure cycle experienced by a number of students [16]. This shows that the disciplinary or punitive classroom management may be contributing to student's misbehavior. On the contrary, soft strategies; such as coaching and mentoring have been known to show the 
Citation: Brown MA, Bourne PA, Peterkin VMS (2019) An Empirical Assessment of Soft and Hard Classroom Management Strategies Employed by Teachers in Secondary Schools in Kingston and St. Andrew, Jamaica. Insights Anthropol 3(1):159-178

softer side of teaching and has also built student/teacher relationships.

\section{Soft strategies?}

Soft strategies, Pedota [17] stated, incorporate the following: the use of a personal approach, fair class rules, positive action, proactiveness, use of positive reinforcement, encouragement and parent's involvement which promotes positive development in students. When the soft strategy is applied it reflects the soft skills such as people skills that highlights the ability to maintain relationship with others, social skills, communication and language skills, interpersonal habits, assertiveness, friendliness, emotional intelligence, and optimism needed to influence people in being successful [18].

Eyster and Martin [19] gave some suggestive ways to integrate caring attitude or soft strategies into the classroom. These are 1) Establish and encourage positive relationship in class: sharing and caring; 2) Use praise as a tool: this can transform the student's image and reinforce positive values that should be displayed in the classroom; 3) Encourage feedback from students: participation in decision making influences positive outcomes; 4) Create a safe learning environment: establish a classroom culture in which students are required to respect each other and safe from occupational hazards; 5) Use a variety of methods to engage students: small group projects, role-playing, debates and journaling; 6) Establish the expectation that everyone must participate in class every day; 7) Give assessment and encourage improvement; and 8) Ensure parent-teacher interaction: giving constant feedback on each student. Soft strategies tend to have a positive impact on students' development but is said to be more effective when incorporated with "hard" disciplinary strategies Reynolds $[20,21]$ which will now be discussed.

\section{What are "Hard" disciplinary strategies?}

Reynolds [20,21] viewed disciplinary strategy as coercive, one in which the teachers use [harsh] measures such as overreliance on punishment to manage their class. Pedota [17], on the other hand, refers to disciplinary strategies as the top classroom management strategies to ensure maximum instruction with few classroom discipline.

\section{Impact of teachers' caring attitude or soft strat- egy on students}

An important variable captured in the hypothesis, "Effective classroom management depends more on the teacher's caring attitude or soft strategies than "hard" disciplinary strategies on disruptive students", which is not well researched is caring attitude. Caring attitude can be linked to the teachers' personality (soft skills), which is not only central to understanding the needs of students, it is also important in understanding the responses of teachers to students [22].

Amongst effective classroom strategies fall student-teacher rapports as well as student interaction within and outside of the classroom, according to Arbuckle and Little [23]. Vitoo [24] classified this rapport as a "relationship-driven classroom": one in which teacher's caring attitude or use of soft strategy builds student's empathy, social skills, communication skills and self-control. Both Vitoo [24] and Arbuckle and Little [23] supported the fact that care restrains poor behavior significantly and enhance student's engagement and satisfaction which are characteristics of a well-organized classroom. This shows that as a part of a teacher's classroom management strategy, they must try to exhibit both a passion about teaching and a passion for the students under their care.

In a research conducted by Williams, Sullivan and Kohn [25], students were surveyed about teachers and what they would like. One of the results stemming from this research was that students want teachers to connect with them by caring about them, showing them that they are important, to actually listen to what they have to say, setting for them high expectations. I believe that this is imperative because if a teacher emphasizes care within her class, classroom misbehavior would decrease and academic performances would increase. Students need for interaction is also significant when considering strategies for one's classroom. Researchers found that students were more engaged in learning and less likely to misbehave when teachers had more interaction with their students regarding instructional matters. Williams, Sullivan and Kohn [25], suggested therefore that teachers showing care towards their student and increasing student interaction through an extensive lesson plan proves to be successful.

One of the most important aspects of teaching students is to ensure that they are actively involved in classroom work and/or activities - they remain on-task. Allowing the students to participate in various activities will keep their minds off anything mischievous, as they would be actively engaged in the instructional process. In the study conducted it was argued that teachers should heighten their delivery methods as students shared that they wanted to have "fun" in the classroom whilst learning.

Research shows that when teachers motivate and engage students, they encourage them to want to learn and channel their energies toward productive behaviours. Students are motivated by teachers who share their excitement about learning. By understanding the different personality types of their students and using appropriate classroom management techniques, teachers can build better relationships with each student [26]. One of the major components of effective classroom management is a positive teacher-student relationship built on mutual respect [7]. When teachers form positive relationships with their students, research has shown that the number of discipline problems decline [7]. The relationship does not have to be one of friendship, and in fact, studies show that students respond more favorably when the teacher provides more guidance instead of being more permissive $[7,27]$.

There is research which focus on Classroom Management Style and Teacher Personality Traits: An educational and psychological interface [28]. Good and Brophy [29] did include an approach to the teachers' classroom management that has some bearing on interpersonal relationship in the classroom. For example, they instruct teachers to speak to students in a positive, and not a negative manner. This study was however measuring the psychosocial needs of the student and not the 
Citation: Brown MA, Bourne PA, Peterkin VMS (2019) An Empirical Assessment of Soft and Hard Classroom Management Strategies Employed by Teachers in Secondary Schools in Kingston and St. Andrew, Jamaica. Insights Anthropol 3(1):159-178

impact of the teachers' attitude, personality and behavior in classroom management [29].

\section{Noninterventionist classroom management}

Noninterventionist (proactive) classroom management is generally geared towards planning ahead to get rid of any behavioural issues before they occur in the classroom. The noninterventionist management can be more constructive than the interventionist strategy and should lead to positive behaviour and the development of self-discipline, thus, the learners' moral behaviour [30]. The noninterventionist may display the rules in the classroom, discuss the required way to conduct oneself in the classroom, and praise good behaviour.

Carl Rodgers and Jacob Koun in are two popular proponents of the proactive (noninterventionist) theory. A brief overview of the philosophy and unique contribution of these noninterventionist (proactive) classroom management pioneers follow. Research for Teachers [31] highlighted his beliefs on classroom management. The research stated, "teachers should seek to create emotionally warm and supportive environments in which they worked collaboratively with their students to achieve mutual goals" [31]. According to Ganly [32], another proponent of noninterventionist management stated that reinforcement is a positive way to discipline students, and it is a helpful tool in the goal of classroom management [33]. Rogers believed in experiential learning, along with self-actualization [31]. Rogers thought if teachers were real, praised their students, showed empathy and understanding (soft skills), then classroom management issues would be obsolete.

Kounin [34] contributed the "ripple effect of discipline" to noninterventionist (proactive) management. Kounin [34], along with the help of Paul Gump and James Ryan, carried out a study over the course of five years to determine "how a teacher's method of handling the misbehaviour of one child influences other children who are audiences to the event but not themselves targets". After watching thousands of hours of videotapes, the researchers were able to discover a teacher's management style can definitely affect how a student behaves. There are various techniques associated with effective teachers, these were highlighted in the research, demonstrating to the students the teacher is aware of everything happening in the classroom, ability to deal with various situations at one time, and dealing with small behaviours immediately.

\section{Impact of teachers' "hard" disciplinary strategy on students}

Walker [27] found that the classroom management style employed by the teacher could impact academic achievement of the students. He studied three different approaches to classroom management: authoritarian, authoritative, and permissive. These styles vary in terms of dominance and nurturance. The authoritative style is described as being high in both dominance and nurturance and produced the highest levels of academic achievement but the authoritarian style is high in teacher dominance but low in nurturance towards students. The permissive style is low in dominance but higher in nurturance [27].

Some research have found that "if we look at the role of a teacher and her contributions to the situation we note a lack of teaching effort focused on developing personal attitude and group standards about good human relations" [35] and that there is evidence that factors in the teachers personal life impact upon the students' academic performance [36]. Stringer [36] also found that just as unusual stress in a child's life is reflected in his behavior and learning performance; unusual stress in a teacher's life is reflected in his or her teaching performance, and may account for much of the year-to-year variations appearing in their patterns". Kane, et al. [37] discussed that students' achievement is impacted by teachers' practices. A teacher's effectiveness is directly related to the academic achievement of his or her students.

Teachers are the most important factor in student achievement but many aspects can cause a teacher to be deemed ineffective. One aspect is a teacher's ability to effectively manage the classroom. If a teacher is ineffective the impact can affect a student's academic career for years. Classroom management includes the actions a teacher must take (a) To foster student involvement and cooperation in all classroom activities, and (b) To provide a productive working environment. A well-managed classroom has a set of procedures and routines that allows the structure in the classroom [38]. In a well-structured classroom, teachers can make significant progress in implementing effective classroom management strategies to create positive learning environments. Thus the need for teachers to be proactive in empowering their classroom management strategies cannot be overemphasized.

\section{Interventionist classroom management}

Interventionist classroom teachers seek to manage the classroom by intervening to shape student behaviour with consequences. Skinner and Bandura two pioneers of this belief, provided a unique contribution to our present understanding of interventionist classroom management. Skinner's Behaviour Management beliefs focused on consequences for behaviour. Skinner believed that behaviour is shaped by the consequences that follow an individual's actions $[39,40]$.

According to Skinner, reinforcements can increase desired behaviours and decrease unwanted behaviours. Types of reinforcements could be social, graphic, tangible, or an activity [41]. Skinner [42] wrote, "Everything we know about operant conditioning is relevant to making behavior more or less likely to occur upon a given occasion. This is the traditional field of rewards and punishment, but much sharper distinctions can be made in taking advantage of what we know about contingencies of reinforcement". Operant conditioning of behaviour is a process of behavior modification in which the likelihood of a specific behaviour is increased or decreased through positive or negative reinforcement each time the behaviour is exhibited, so that the subject comes to associate the pleasure or displeasure of the reinforcement with the behaviour $[43,44]$. Skinner [42] implied that a teacher can control the classroom environment through instantaneous reinforcement. These 
Citation: Brown MA, Bourne PA, Peterkin VMS (2019) An Empirical Assessment of Soft and Hard Classroom Management Strategies Employed by Teachers in Secondary Schools in Kingston and St. Andrew, Jamaica. Insights Anthropol 3(1):159-178

reinforcements can come in positive (special opportunities, celebrations, candy) and negative (loss of opportunities, office referrals, in school suspension, out of school suspension) forms to create an environment where each student works productively. Skinner [42] closed with a concept, “...problems can be solved, even the big ones, if those who are familiar with the details will also adopt a workable conception of human behavior".

From the behaviourist view of Skinner, the student's behaviour can be shaped by consequences. However, a classroom has more than one student at a time, and learning can occur vicariously. To extend the behaviourist concept of learning from consequences to include learning by observing the consequences of the behaviours of others, a social learning theory was needed.

Albert Bandura developed the Social Learning Theory built around the view that people learn appropriate and inappropriate behaviours from each other [45]. Bandura $[46,47]$ thought that students learn through their perceptions and imitations of certain behaviours demonstrated by parents, teachers, or other students. Bandura believed that, as behaviours were exhibited, individuals would emulate one another $[45,47]$. This theory has important implications for classroom management.

According to Bandura's $[46,47]$ Social Learning Theory, people acquire a self-efficacy or a self-belief system, which allows them to possess self-control of their thoughts, actions, inspiration, drive, and feelings throughout various levels of life. Bandura characterized self-efficacy as the "beliefs in one's capability to organize and execute the courses of action required to manage prospective situations" [47]. Social Learning Theory also emphasizes the importance of student perceptions in the learning process with an emphasis on the idea that people frequently acquire knowledge, rules, skills, strategies, beliefs, and attitudes by watching others [46]. Therefore, social learning is important in classrooms.

Bandura [47] believed that self-efficacy persuaded the choices people make because a person's experiences and learning from others are the groundwork through which a person reveals his or her behaviour. "Efficacy beliefs are the foundation of human agency. Unless people believe they can produce desired results and forestall detrimental ones by their actions, they have little incentive to act or to persevere in the face of difficulties" [48]. Bandura [47] offered "triadic reciprocal causation" as an identifier for justifying how one's personal behaviour and uniqueness, along with the surrounding environment, work together to make people both products and producers in their environments [47]. This triadic reciprocal causation is the interaction between thought, influence, and action [47] in what people believe, think, and experience that determines how they behave $[46,49,50]$. Efficacy forwards that a person possesses regarding their skills, influence their actions in the present and future. Bandura's theory is the foundation for classroom management strategies that center on the idea that students learn from each other and that teachers can shape a student behaviour by influencing others in their social environment.

\section{Classroom management strategies and its rela- tion to teacher's socio-demographic}

Very few literatures can be found on how classroom management strategies relates to teacher's socio-demographics. Socio-demographics in this study will relate to the following, based on teacher's: age-group, gender, educational level, years of teaching experience, level of school taught by teachers and their choice of shifting to another profession.

Teacher's age-group: As it relates to teacher's age-group, no literature was found directly related to this variable based on the hypothesis being researched. Nevertheless, this variable may provide some understanding of teachers' willingness to employ a particular strategy over the other. The age factor holds a critical role in human existence and may aid in deepening knowledge of teachers' practice-behaviour in schools.

Teacher's gender: A teacher is individually recorded by his/her gender type, female or male. Research conducted by Glasgow and Hicks [51] highlighted that female teachers were preferred over their male counterparts. Evans [52] found that 'female teachers' students outperformed male teachers' students in the area of math and reading, as measured by the MAP assessment in Grades K-8". Based on the above-mentioned literature, it was found that students' achievements were linked to effective classroom management in keeping with the teacher's effective use of soft and "hard" disciplinary strategies.

Teacher's education level and years of teaching experience: Several studies have been conducted that investigated the relationship between teacher education level and years of teaching experience on student achievement on a specific subject, science [53-55] and [56]. Their research will be utilized to explain the hypothesis and their control variable (science and math subject) will not implicate this study.

Teacher's education: Teacher's education level refers to the highest level of education that a teacher obtains, whether it is degree or masters. A factor contributing to poor students' achievement is unqualified teachers, according to Goldhaber [57]. Greenberg, et al., [58] stated that teachers who possess a master's degree may have a greater impact on students' achievement. However, this was disputed by Goldhaber and Brewer $[53,54]$ and Ye $[55]$ who opined that a teacher having a master's degree in science or education was not a statistically significant predictor of student achievement in [science] than teacher's holding a teaching certificate. This is to say that you can get the same results from students' achievement regardless of what degree you possess. According to Goldhaber and Brewer [53,54], teachers with bachelor's degrees in the subject area that they taught gained a significantly higher achievement scores from students.

Teacher's experience: Goldhaber \& Brewer [53,54], and Ye [55] found that teachers with more years of teaching experience were no more effective than those with fewer years of teaching experience. On the contrary, Zhang [59] postulated that teachers having more years of experience teaching one particular subject will have a greater impact on student achievement in that subject than those teachers who have fewer years teaching that subject. There has been a long 
Citation: Brown MA, Bourne PA, Peterkin VMS (2019) An Empirical Assessment of Soft and Hard Classroom Management Strategies Employed by Teachers in Secondary Schools in Kingston and St. Andrew, Jamaica. Insights Anthropol 3(1):159-178

history on the impact of teaching experience in classroom management both in the elementary and secondary/high school [60].

Hawkins, et al. [56] reported on the effects of teacher experience on student achievement in primary school and found that students who had teachers with five or more years of experience teaching math were more likely to perform better. Richardson [61] also found that students taught by experienced teachers attain significantly higher achievement levels than do students who have new teachers with one to three years of teaching experience.

Research consistently shows that teachers new to the profession make important gains in teaching quality in their first year teaching, and then smaller gains over the next few career years. However, no consistent linear relationship exists between years of teaching experience and student achievement after three initial years of teaching, which makes it more difficult to determine if there are any discernible differences among more veteran teachers-for instance, between teachers who have 7-10 years of experience and teachers with 20 or more years of experience [62-64].

\section{The effectiveness of soft strategies and "hard" strategies on classroom management}

According to Stein [65], the training most teachers receive is in managing students, but to successfully achieve, there must be a balance. Students also need teachers to lead and guide them in ways they would not have learnt, if they were on their own. Classroom managers, teachers must, also, have organization skills, discipline, show respect to the students, communicate appropriately, create and have high expectations, develop trust between themselves and the students, offer praise, listen, and design meaningful challenges [66]. In fact, some solutions which have been recommended by McDaniel, Yarbrough \& Ruma [16] to improve classroom management have to do with problems with teachers' behaviour as shown below:

1. To reduce a negative classroom climate, teachers should increase praise with self-monitoring,

2. To reduce power struggle, teachers should use peer mentoring and observation, and

3. Where there is a lack of respect, teachers should develop a praise and re-enforcement schedule.

\section{Effective classroom management strategies en- hance learning}

A positive school/classroom climate is defined as those collective beliefs, standards and attitudes that shape interactions between students, teachers, and administrators and set the parameters of acceptable behaviour and norms for the schools [67]. This sets the tone for a positive school [classroom]. School climate has been linked to academic achievement whether academically or otherwise as well as shaping many undesirable behaviours. The author strongly states that, classroom management strategies allows for teachers to maintain control over students through the use of discipline and encouraging positive environments that foster academic learning and desirable conduct. Furthermore, the teachers' use of classroom management strategies may increase/improve students' opinions of a positive school climate. Paul Pedota [17] posited that before the teaching process begins, adequate time must be spent devoted to preparation, and developing procedures, that will inevitably maximize instruction and enhance learning in a climate that is positive. Based on the information, the researchers were able to further explore effective classroom management strategies that teachers should use in their classrooms.

One of the most important aspects about classroom management strategies is that it must be enforced; teachers must also be consistent and confident, not only in their teaching, but also in the strategies that will be used in the classroom. Marzano, Marzano, and Pickering [68], believed that a crucial element in effective teaching is effective classroom management. It has been recognized that as a teacher you cannot obtain student's full cooperation and involve them in instructional activities, without it is unlikely that effective teaching will take place. Therefore, it is important that if teachers want success not only in their career, but also in their classrooms and student's academic achievements, there are steps that must be taken prior to the actual teaching. There is not just one strategy that can be used that will ensure all students learn; neither are their multiple strategies teachers can use that will guarantee that all students in his/her classroom will succeed. Difficulties at home and in other spheres that the students face will automatically which spill over into the classroom. Though teachers should understand and become aware of the diverse situations their students face, management strategies should still be implemented to ensure that effective teaching takes place.

Researcher and educator Paul Pedota [17] postulated that the teacher with fewer disciplinary problems are those teachers who spend extensive time in planning and considering the diversity of their student and their learning styles. Having read so many different literatures, I found that the top management strategies are those which create a positive environment, planning and ensuring that there is sufficient work for all students that will keep them on-task. Understanding the students, creating a positive teacherstudent rapport, and establishing classroom rules, seating arrangements as well as a balance between discipline/ punishment and rewards prove to be beneficial strategies for teachers as well. Being a former teacher, Rischer [69], articulated that the collective use of management strategies really helps teachers manage diverse classrooms with ease. Teachers who are confident will teach with determination and will get students to model their behaviour and allow them to want to learn. Teachers then have to be aware of their weaknesses and limitations and plan accordingly.

\section{Methodology}

\section{Introduction}

Green and Henriquez-Green [58] opined that "New teachers and veteran teachers have, for years, stated 
Citation: Brown MA, Bourne PA, Peterkin VMS (2019) An Empirical Assessment of Soft and Hard Classroom Management Strategies Employed by Teachers in Secondary Schools in Kingston and St. Andrew, Jamaica. Insights Anthropol 3(1):159-178

that the number one problem they faced had to do with classroom management" (p. 2.4), which is no different in Jamaican secondary/high schools. The current study seeks to examine the utilization of hard and soft strategies by Jamaican teachers in the class as they seek to carry out their mandate. Hence, this chapter is a detailed review of methods and materials associated with conducting the study. The various themes and sub-themes that will be examined in this section include research design, ethical consideration, sampling, delimitations and limitations, data collection and data analyses. Therefore, a positivistic knowledge claim will be used to evaluate the topic "Evaluating the classroom management strategies employed by teachers in twenty secondary schools in Kingston and St. Andrew" in an effort to answer the following research questions: main questionDo teachers employ more soft than hard strategies in the management of their classroom in twenty secondary schools in Kingston and St. Andrew, Jamaica? and sub-questions-1) Are Jamaican teachers employing hard and soft-strategies in their classrooms? 2) Does the employment of hard and softstrategies by teachers in their classroom differ based on sociodemographic characteristics? 3) Is there a correlation between the employment of hard and soft strategies by Jamaican teachers in their classroom? 4) Does the employment of hard and soft-strategies by teachers in their classroom differ based on who is responsible for the employment of the strategies in the classroom, introduction of school rules to new students in the class, who normally reminds the students of the rules?

\section{Research design}

The research design for the present work is a descriptive one in which the researchers relied on numbers and so objectivism will be employed. The study is quantitative research using a standardized instrument (i.e., questionnaire) comprised of 45 questions which was designed for the purpose of capturing the respondent's thoughts through closed ended responses. The researchers used the opportunity to interview some of the teachers in a bid to gain information which may not have been represented on the questionnaire. The instrument was sub-divided into sections intended to collect data on 1) Respondents' demographics (questions 1-6); 2) The effectiveness of specific classroom management strategies which are deemed to be disciplinary in nature, how early these are introduced to the classroom and the method of sensitizing the children to the strategies (questions 7-9), and 3) How effective are other strategies which may be innately linked to the teachers' personality versus the institutional disciplinary system. The responses will measure how the teachers view the effectiveness of each (10-45).

Finding out about teachers' perception of these classroom management strategies and their impact on student behaviour may indicate their own attitude and commitment towards using them. They could also shed some light on the values place on disciplinary versus soft skills in our institutions.

\section{Population and sampling}

The population for this research is all teachers in Jamaica who are employed with a secondary high school. The sample was chosen solely based on two criteria. These are 1) Teachers; and 2) An individual currently teaching in secondary schools in Kingston and St. Andrew. Thus, participants who fulfilled those criteria were part of the sample. The nature of this study is such that, the researcher chose participants based on their willingness to participate in the research process and them meeting the conditions for inclusion in the study in order to meet the general objective of the work-convenience sampling [70]. Convenience sampling techniques were employed to select teachers who were available and willing to participate in the study because of time constraint.

The logic of sampling is to make inferences about the population [71,72]. Unlike quantitative approach in which there is a huge emphasis on probability sampling for representation, qualitative research design often utilizes non-probability sampling as well as instances for quantitative research whenever the population is difficult to ascertain. In non-probability sampling, the researchers strive to create a "kind of quasi-random sample, and/or to have a clear idea about what larger group or groups the sampling may reflect" $[71,73]$. For this study, it would have been costly to employ a probability sampling frame and so the researcher opted for a non-probability sampling frame because it was cheap and at the same time provides critical data for useful analyses.

According to Leedy and Ormrod [74] a convenience sample takes people or other units that are readily available. Creswell [75], further stated that participants are selected because they are willing and available to be studied, hence the twenty secondary schools chosen to participate in this study. As such, participants who are not cognizant of the issues of this research could offer any assistance and therefore were not used [73]. Thus, fifty (50) participants were separately interviewed by the researcher and his-team.

\section{Study Setting}

Urban government operated secondary schools are the target of this study. The schools' population accounts for 889 teachers-1) 389 from non-traditional secondary schools, 2) 425 from traditional high schools and 3) 75 from private secondary high schools. The teachers are assigned to grades 7-to-12. The approximately $59 \%$ of the sampled teachers taught in non-traditional high school. For this research, the participants were chosen solely on the basis of two criteria outlined in population and sample section. A quiet room was selected to conduct the research. This room was in close proximity to the guidance counselor's office. It was secluded and provided complete privacy, so as to create an environment where the teachers could feel safe in expressing themselves truthfully.

\section{Pilot study}

One of the philosophical assumptions of knowledge is that no one is the sole holder of truth, wisdom, understanding and experience in this vast and complexed socio-physical world $[70,76]$. As such, requesting assistance from experts in the field from other authorities; and pilot testing instruments go a far way in understanding the final quality of the items. 
Citation: Brown MA, Bourne PA, Peterkin VMS (2019) An Empirical Assessment of Soft and Hard Classroom Management Strategies Employed by Teachers in Secondary Schools in Kingston and St. Andrew, Jamaica. Insights Anthropol 3(1):159-178

Hence, the researcher consulted research books such as Basics of Quality Research by Anselm Strauss and Juliet Corbin [77]; Qualitative inquiry and research design: Choosing among five approaches by John Creswell [70]; The Practice of Social Research $10^{\text {th }}$ Edition by Babbie [73], and Social Research Methods: Qualitative and Quantitative Approaches, $6^{\text {th }}$ edition by Neuman [78] as they provided some conceptual and technical guide in research process, especially itemizing questions for an instrument. One of the recommendations by all of the aforementioned methodologists is piloting testing the actual instrument in order to ensure readability, understandability, validity of the items, and most of all do the items actually measure the intended research question. The researchers complied with the recommendations of the scholars, in order to improve the quality of this study.

On reviewing Creswell's work, in attempting to design an instrument [70], the validity and reliability of the items on the instrument was paramount in the data collection process. Hence, pre-testing of the instrument for 1) Simplicity, 2) Readability, 3) Understanding of issues, 4) Ensuring the concepts are measuring the content of items they are supposed to evaluate, and 5) Correct errors before the final instrument is published. As a result, a pilot study was conducted to examine the aforementioned issues with some fifteen-teachers from a certain non-traditional as well as a traditional secondary high school in Mandeville, Manchester, Jamaica. They were asked to examine the content, phraseology of the instrument, and the participants made some suggestions and these were incorporated in the final items and helping to enhance the accuracy of the questions. The interview protocol is, therefore, presented below in order to provide information on the instrument.

The exercise is estimated to last for thirty-to-forty-five minutes. The respondents were coded and put into the computer. This was done to determine the validity, reliability and internal consistency of the items. Modifications were made to the initial instrument based on the feedback given by the supervisor/methodologist as well as the actual piloted respondents. The input was fed back into a modified instrument to formulate the final questions. Cronbach alpha was used to examine the validity of Likert scale indices and these are as follows: 0.85 for hard strategies index and 0.72 for soft strategies index.

\section{Ethical Consideration}

The social science is an inquiry into social phenomena, meaning peoples' attitudes, behaviours and perceptions. Because social science is on people, care must be taken in how the information is gathered $[73,78]$. To comprehend the seriousness of ethical issues, in Neuman's book entitled "Social Research Methods: Qualitative and Quantitative Approaches' chapter 5 reads 'The Literature Review and Ethical Concerns', suggesting that document analysis which provides the context for scientific investigation must take into consideration ethical standards that hold true throughout the research process [79]. Neuman opined that "researchers need to prepare themselves and consider ethical concerns as they design a study so that sound ethical practices are built in to the study design" [78]. Neuman noted further that "ethics define what is or is not legitimate to do, or what "moral; research procedure involves" [78].

The researchers collected a permission letter from the office of Graduate Studies seeking permission for the researchers to conduct the study at the prescribed school. The letter stated the objectives and the duration of the intervention, the target group and the purpose of the study. The researchers made it known to the principal that the school's name and subjects' names would not be mentioned in the study. The researcher also informed the principal of one of the benefits of this intervention programme which is to help administrators to make meaningful decisions as to which teaching approach would best fit the subjects in order to improve performance. In addition, participants were informed of their rights and responsibility of the subjects, and that they can withdraw from the process if they so desire. An informed consent form was given to each willing subject to sign before they were allowed to participate in the research. Another ethical issue that was taken by the researcher is the exclusion of students' names from comments, the exclusion of the school's name, students were asked not to provide any names or label that can be traced back to them, and the transcripts were kept in a vault.

\section{Data Collection Procedures}

A standardized instrument (or survey) was used to collect the data from the sampled respondents. The study was conducted at twenty (20) secondary schools in Kingston and St Andrew. Permission was obtained from the principals of all the schools who agreed to have their teaching population participate. Despite being granted permission there was still a challenge getting some teachers to devote the time to interact with the researcher. Some even joked about not being able to "scratch their heads" and not seeing the value in participating. Some were of the opinion that children's' misbehavior will not be impacted by anything they or the government does.

After overcoming the initial delay, the processes went smoothly as the researcher explained that the teachers were largely expected to respond on the questionnaires, only a select few will be asked to participate in a brief fifteen (15) minutes interview as part of focus group discussion. They were fully briefed on the content of the questionnaire and told that the matters which would be discussed in the focus groups were pertaining to classroom management strategies which may not have been captured by the questionnaire.

The researchers had no questions for the students in schools because they were not the focus of this study. They were however made aware of the reason for the study, in a bid to reduce the taunts coming from the classes surrounding the "teachers being under investigation". All participants were told that their participation was completely voluntary and anonymous. Some of the questions used in this questionnaire were adopted from the Teacher Classroom Management Strategies Questionnaire developed in 2012 by the "incredible Years". This may be retrieved from www. incredibleyears.com. All the questions were closed ended in 
Citation: Brown MA, Bourne PA, Peterkin VMS (2019) An Empirical Assessment of Soft and Hard Classroom Management Strategies Employed by Teachers in Secondary Schools in Kingston and St. Andrew, Jamaica. Insights Anthropol 3(1):159-178

order to limit the number of responses for analytical purpose. While questions 1-9 mainly focused on getting to know each respondent and the general mode of classroom management communication in each school, the bulk of the survey focused on the effectiveness of soft versus hard disciplinary strategies. The effectiveness is measured on a scale of 1 to 5 with 1 being poor and 5 being excellent. The responses to these questions (10 to 45 ) will also be used to measure the frequency of which the teachers utilize each strategy.

\section{Data Analysis}

The collected surveys were entered, stored and retrieved using the Statistical Packages for the Social Sciences (SPSS) for Windows, Version 25.0. SPSS was used to provide descriptive statistics (i.e., frequency, mean, mean, standard deviation) followed by bivariate analysis (i.e., Pearson's Product Moment correlation, which test the association between the employment of hard and soft strategies) and multivariate analysis (i.e., univariate analysis of selected variables on selfperceived soft strategies employed by teachers) as well as graphical presentations (i.e., bar and pie graphs). In order to establish statistical association and difference, a p value of $5 \%$ was used to determine statistical significance.

Apart from the demographic, the questionnaire was designed to capture various dimensions of the teacher's effectiveness in classroom management in an effort to detect any leaning towards social actions which can be defined as soft or hard strategies. It is still a fact that many teachers were distressed with the ineffectiveness of classroom management and teacher stress and negative emotion are often related to student misbehavior [79]. First, questions 10-11 were designed to capture the teachers' ability to manage their classrooms, and to determine the psychological framework of the teacher in promoting students emotional, social and problem solving skills.

Questions 12 to 25 were designed to capture the teacher's feedback on the effectiveness of classroom management strategies which are defined as "hard, disciplinary" strategies. It has also been discovered that teachers who are more likely to use negative and punitive strategies to curb disruptive adolescent behaviour are more likely to experience poor classroom management as this corrodes teacher-student relationships and can add to the failure cycle experienced by a number of students [16]. These are the ones which may negatively impact the teacher/student relationship. Research has found that "teachers who are highly skilled in classroom management spend more time in engaged instruction, use less exclusionary discipline and promote positive student development" [16].

Upon collecting the questionnaires and the notes from the focus group sessions, the data was transcribed and coded according to subject areas addressed and trends which emerged. The data was analyzed and processed into the results which appear in this study.

\section{Delimitations}

There are always going to be issues that arise whenever a research is being conducted and this study is no different from others. Delimitations are likely to arise in this research which will narrow the scope of the work [70]. The sampled schools of this study were selected totally based on the researcher's knowledge of the area in which the institutions are located. The schools are located the Kingston and St. Andrew area, which are in close proximity the researcher's residence and place of work. With the intent of the being able to explore the perception of teachers as it relates to strategies employed in the classroom, participants for the study were delimited to teachers of particular secondary schools are exposed to similar experiences.

\section{Limitations}

On examination of Creswell's work on research, the issue of limitations of a research was addressed and the one relating to this paper will be discussed. For this study, the limitations that arise are non-generalizability which is due to 1) Small size, and 2) Non-probability sampling design.

1. The conduct of the study was met with certain limitations. First, limitation is that the study relied only on teachers' self-reported data. It would have been more preferable to support teachers' self-reported data with a variety of measurement tools, such as direct observation and interviewing participants;

2. A second limitation is related to the population of the study. The population of this study is limited to the secondary school teachers working in Kingston and St Andrew. As such, the results of the study cannot be generalized directly to all secondary school teachers across Jamaica. The results can only provide us with insights and a general opinion from this specific sample;

3. The researcher received non-responses from some participants hence this impacted the sampling size which greater affected the accuracy of the study. As such, discussions were mainly based off the literature review combined with the other participants' response which were collected and analyzed;

4. The researcher excluded the independent variable making it difficult for a better assessment of the area studied and for a more effective study;

5. The questionnaire did not carry any guideline to participant; making it difficult to be reused for similar studies;

6. The questionnaire would be more effective, if students were asked to respond to questions to ascertain how the different strategies impacted them. It would make the research stronger;

7. The time of day sessions affected the students' behavior and productivity;

8. The teacher needed time to adjust to the researcher method of instruction, classroom and behavior management; and,

9. Finally, the study did not examine how the caring attitude or soft strategies and "hard" disciplinary strategies influence the learning outcome that is performances. 
Citation: Brown MA, Bourne PA, Peterkin VMS (2019) An Empirical Assessment of Soft and Hard Classroom Management Strategies Employed by Teachers in Secondary Schools in Kingston and St. Andrew, Jamaica. Insights Anthropol 3(1):159-178

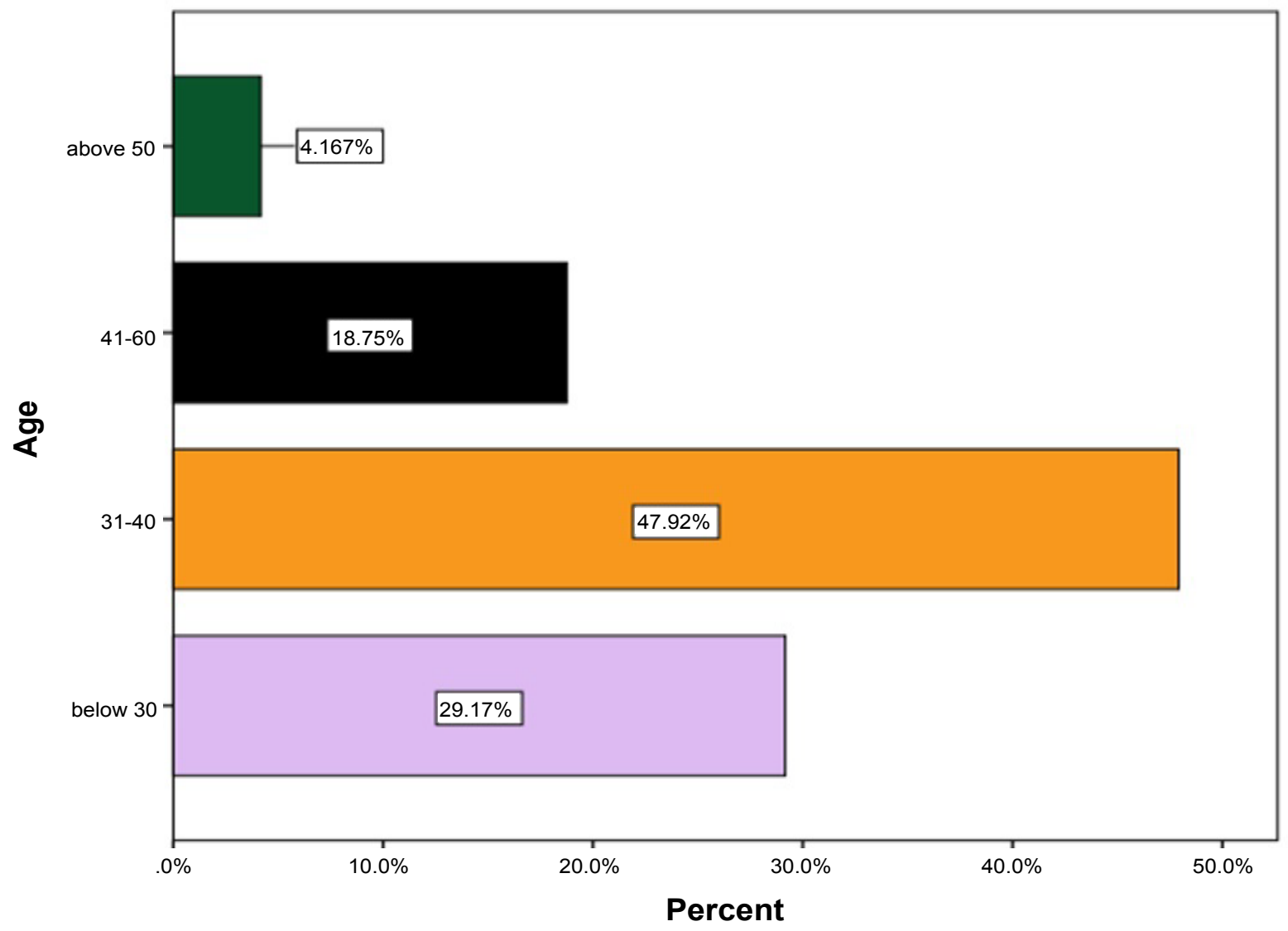

Figure 1: Age group of respondents.

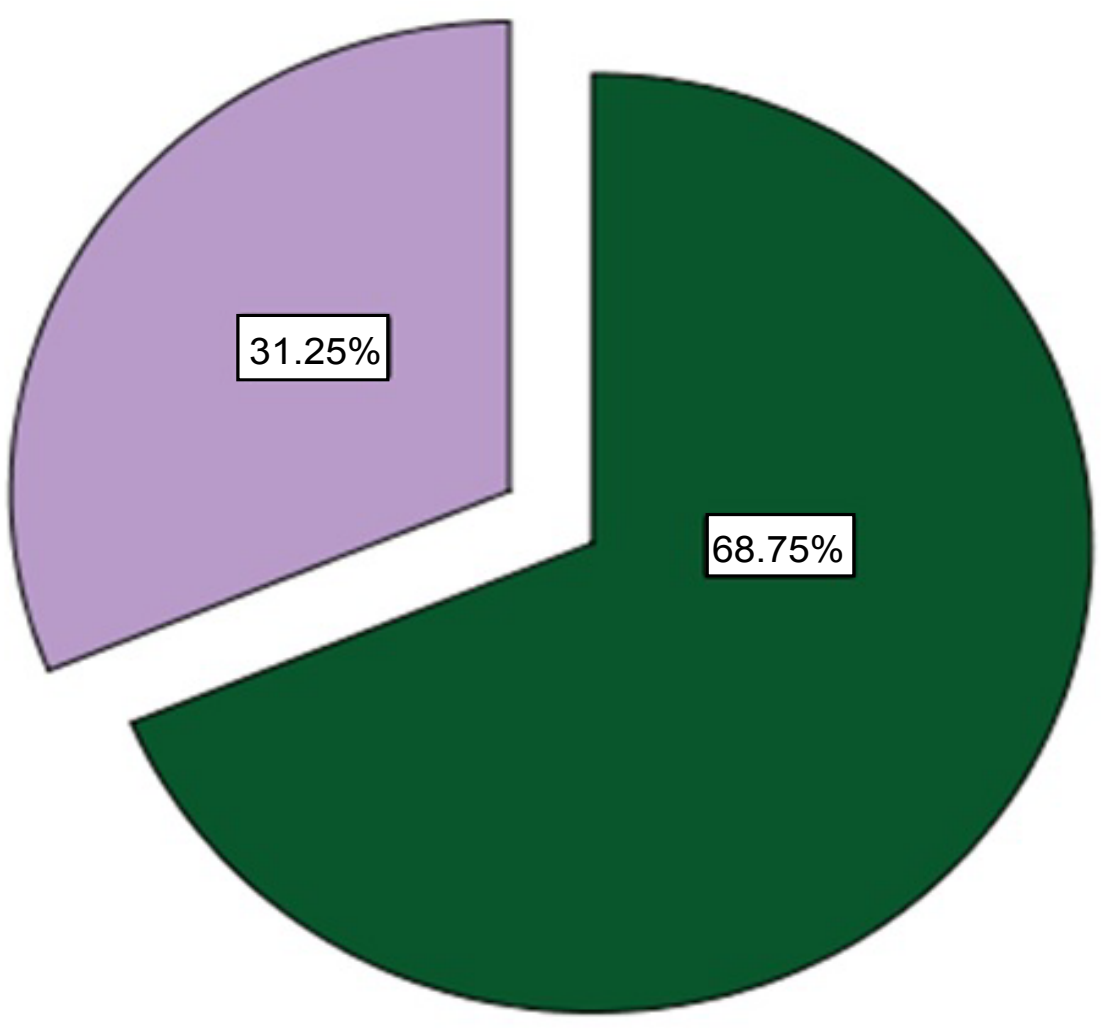

\section{Gender \\ $\square$ male \\ female}

Figure 2: Gender composition. 


\section{Findings}

\section{Socio-demographic characteristics of sampled respondents}

Figure 1 depicts a bar graph of the age cohort of the sampled respondents. There were 48 sampled respondents for this study. Of the sampled respondents $(n=48)$, the majority of the respondents $(n=23,47.9 \%)$ are in the age group of 31 40 years, with only $4.2 \%(n=2)$ being $50+$ years old.

Of the sampled respondents $(n=48), 68.8 \%(n=33)$ were males compared to $31.2 \%$ being females which is depicted in Figure 2. The gender composition of the sampled respondents reflects the sex-ratio disparities in those who teach at secondary/high schools in the Kingston and St. Andrew region in Jamaica.

The educational level of the sampled respondents is depicted in Figure 3. The majority of the sampled respondents ( $n=30,62.5 \%$ ) had obtained a Bachelor's degree compared to $27.1 \%(n=13)$ with at least a Master's degree. It can be deduced from the findings that 9 out of every 10 respondents have obtained at least a Bachelor's degree and this speaks to the high content availability among the teachers in this survey.
When the respondents were asked "How many years have you been teacher?" marginally more of them had between 11 and 20 years of experience in teaching ( $n=17,35.4 \%$ ) compared to those with less than 5 years $(n=, 13,27.1 \%)$ and only $12.5 \%$ had $20+$ years' service in teaching (Figure 4 ).

Figure 5 depicts a bar graph on the highest level of teaching experience of the sampled respondents, which is represented by way of percentages in each category. Of the sampled respondents $(n=48)$, most of them had taught at the secondary/high level $(n=20,41.8 \%)$ followed by the primary level $(n=15,31.3 \%)$.

To the question "If given the chance, would you choose another profession?" the response to issue is depicted in Figure 6. Most of the respondents indicated that if they had an opportunity, they would want to change their profession ( $n=32,66.7 \%$ ).

The respondents were asked the question "Who do you think are most responsible for introducing classroom management rules to a new class (rank in order of most responsible if you choose more than one)" and the responses are presented in Table 1. Of the sampled respondents $(n=$ 48 ), the form teacher ( $n=25,52.1 \%$ ) was indicated as the Bastian for introducing classroom management rules of new students followed by the Dean of discipline ( $n=15,31.3 \%$ ),

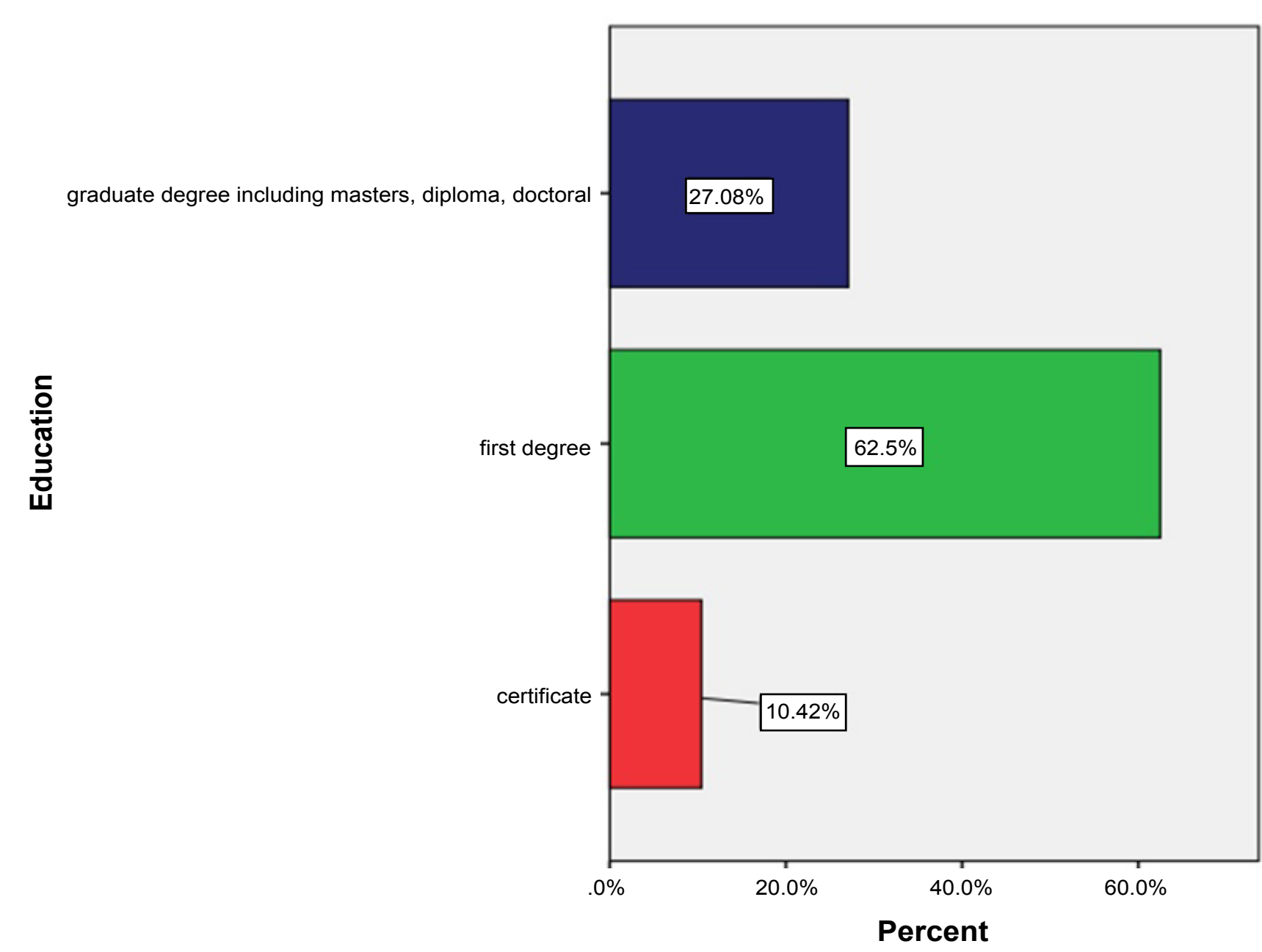

Figure 3: Educational level of respondents. 
Citation: Brown MA, Bourne PA, Peterkin VMS (2019) An Empirical Assessment of Soft and Hard Classroom Management Strategies Employed by Teachers in Secondary Schools in Kingston and St. Andrew, Jamaica. Insights Anthropol 3(1):159-178

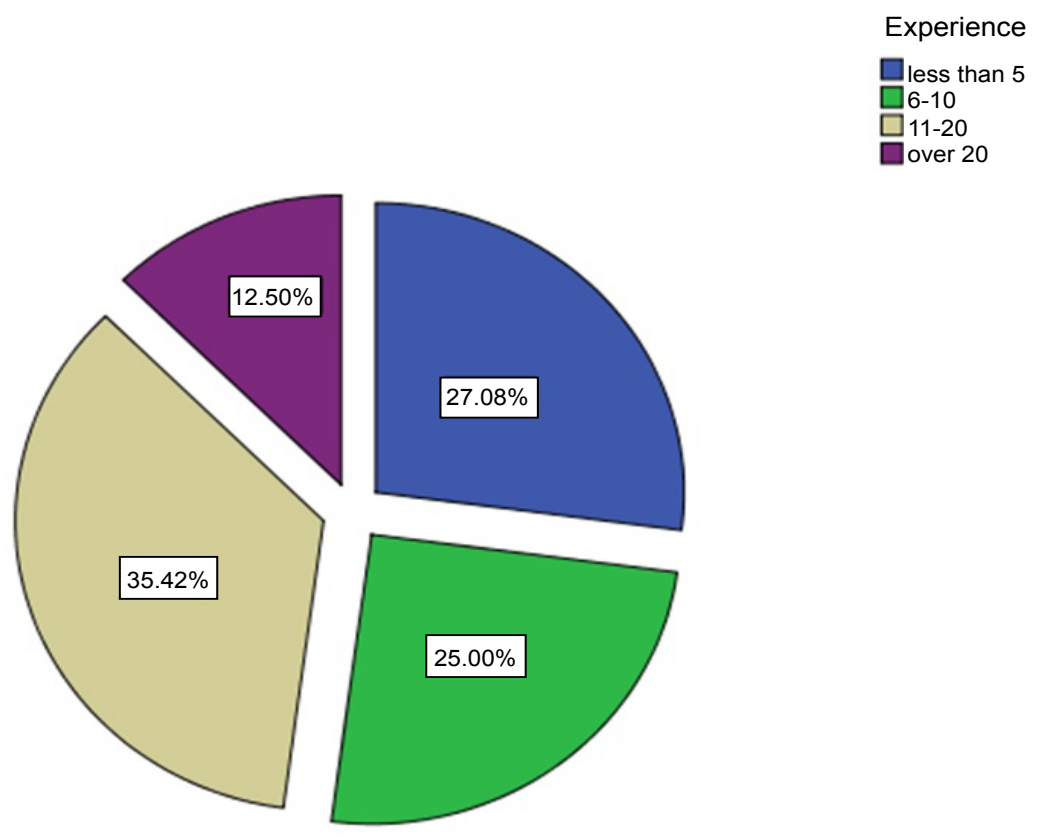

Figure 4: Teaching experience.

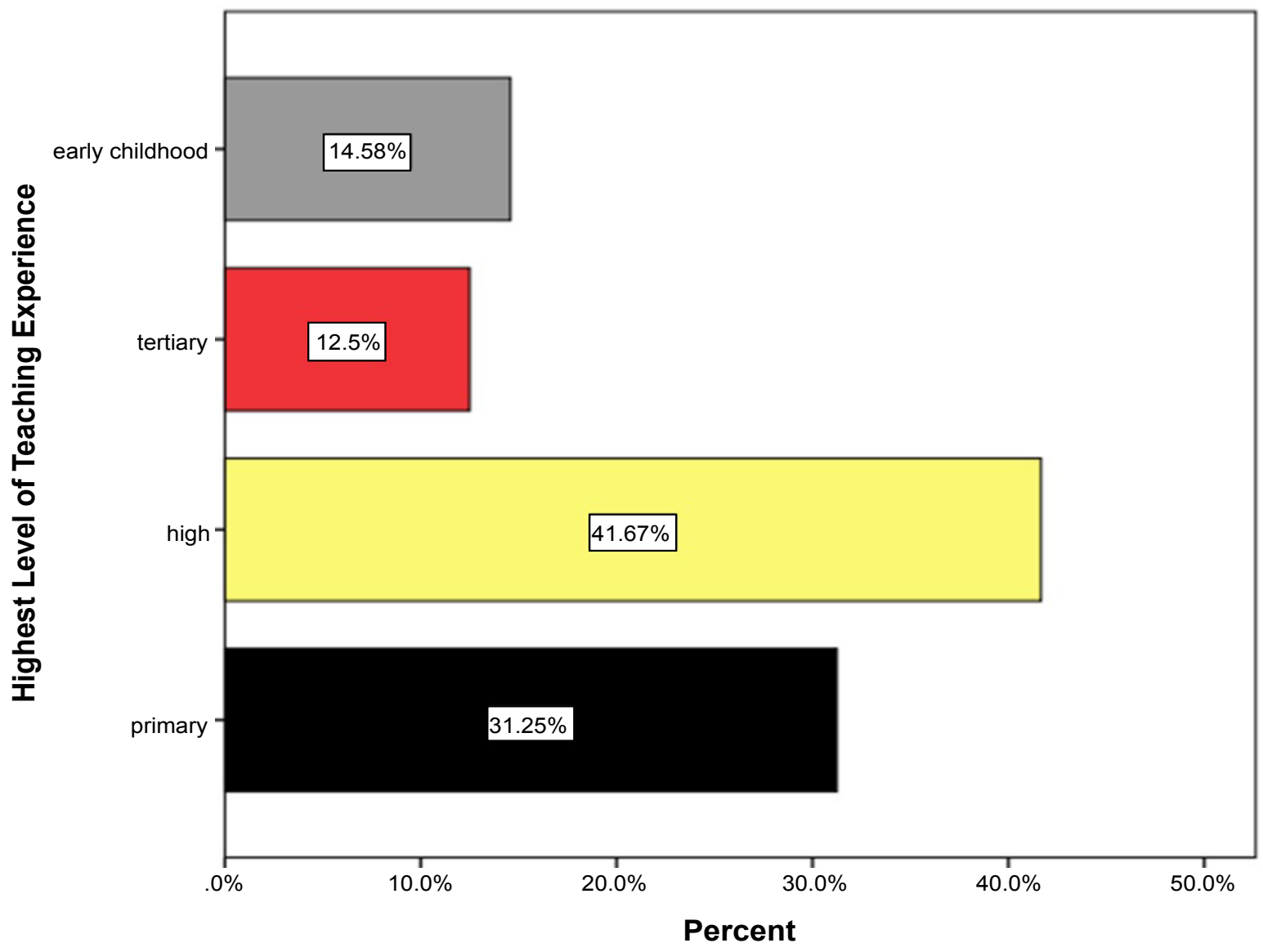

Figure 5: Highest level of teaching experience.

and so forth (see Table 1).

The respondents' perspective on "How early is classroom management rules introduced to a new class?" range from first day of class to first day of the semester. Close to $60 \%$ of them indicated the 'first day for all students, only' and this more are presented in Table 2. This denotes that classroom 
Citation: Brown MA, Bourne PA, Peterkin VMS (2019) An Empirical Assessment of Soft and Hard Classroom Management Strategies Employed by Teachers in Secondary Schools in Kingston and St. Andrew, Jamaica. Insights Anthropol 3(1):159-178

management of the rules of the school are not carried out on a continuous basis and that some students may miss this experience simply because they are absent on the first day of school or for the semester.

Table 1: Perception of who is responsible for introducing classroom management rules to students.

\begin{tabular}{|l|l|}
\hline Details & Frequency (n) \\
\hline Dean of discipline/Principal & $15(31.3)$ \\
\hline Parents & $2(4.2)$ \\
\hline Form teachers & $25(52.0)$ \\
\hline Subject teacher & $6(12.5)$ \\
\hline Total & $48(100)$ \\
\hline
\end{tabular}

Table 2: Earliest of the classroom management rules to a new class.

\begin{tabular}{|l|l|}
\hline Details & Frequency (n) \\
\hline First day for new students only & $6(12.5)$ \\
\hline First semester only & $2(4.2)$ \\
\hline First day for all students only & $28(58.3)$ \\
\hline First semester for all students only & $8(16.7)$ \\
\hline Adhoc basis & $4(8.3)$ \\
\hline Total & $48(100.0)$ \\
\hline
\end{tabular}

Table 3: Respondents' perception of normalcy of reminding students of classroom rules.

\begin{tabular}{|l|l|}
\hline Details & Frequency (n) \\
\hline Official notices & $8(16.7)$ \\
\hline Word of mouth & $32(66.7)$ \\
\hline Sent to parents & $4(8.3)$ \\
\hline Head boy/girl, prefects, student councilor & $3(6.3)$ \\
\hline Guided by peer & $1(2.1)$ \\
\hline Total & $48(100.0)$ \\
\hline
\end{tabular}

Table 3 disaggregated data on the question posed to respondents on 'How students are normally reminded of the classroom rules?' Of the sampled respondents $(n=48), 2$ in every 3 indicated word of mouth compared to official notices $n=8,16.7 \%$ ). It can be extrapolated or deduced from Table 3 that there is a lack of continuity of the official school system to impart rules to students and that schools rely informal strategies to communicate their rules to students.

Research question 1: Are Jamaican teachers employing hard and soft-strategies in their classrooms?

\section{Hard and soft strategies}

Table 4 presents descriptive statistics on two indices-1) Self-perceived hard strategies index employed by respondents and 2) Self-perceived hard strategies index employed by respondents. On average, self-perceived hard strategies employed by respondent was $37.6 \pm 7.3,95 \% \mathrm{Cl}$ : $35.4-39.7$. On the other hand, self-perceived soft strategies employed by respondent was highly practiced $(85.9 \pm 12.8,95 \% \mathrm{Cl}$ : 82.2 89.6), with the maximum score being 109.0. Comparatively, the respondents marginally practice more soft than hard strategies in Jamaican secondary schools.

Strategies in the classroom management were, have been, and continue to be a topical issue in the teachinglearning process simply because they hold the key to learning outcomes. The literature has shown that educators employ soft and hard strategies in their classrooms to deal with various issues that arise from time to time $[17,20,24,25,68]$. In fact, a group of scholars opined that "teachers who are highly skilled in classroom management spend more time in engaged instruction, use less exclusionary discipline and promote

Table 4: Descriptive Statistics of self-perceived hard and soft strategies.

\begin{tabular}{|l|l|}
\hline Details & \\
\hline Self-perceived hard strategies & $37.6 \pm 7.3,95 \% \mathrm{Cl}: 35.4-9.7$ \\
\hline Self-perceived soft strategies & $85.9 \pm 12.8,95 \% \mathrm{Cl}: 82.2-89.6$ \\
\hline
\end{tabular}

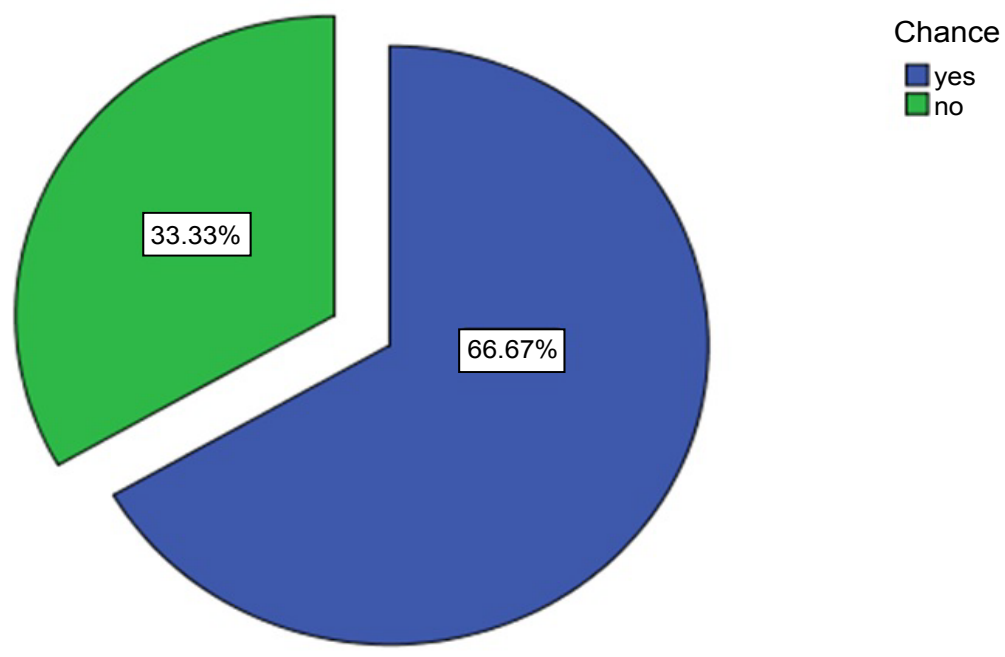

Figure 6: Would you choose another profession. 
Citation: Brown MA, Bourne PA, Peterkin VMS (2019) An Empirical Assessment of Soft and Hard Classroom Management Strategies Employed by Teachers in Secondary Schools in Kingston and St. Andrew, Jamaica. Insights Anthropol 3(1):159-178

positive student development" [16]. It can be deduced from the McDaniel, et al.'s perspective that educators utilize both soft and hard strategies in their classroom, with which the current study concurs.

According to Reynolds [20] as cited by Ayers and Gray [21], "soft strategy" termed as an "incorporative strategy in which teachers enable the students to acquire a sense of responsibility for their learning and behavior". In fact, research has shown the employment of soft strategies in a Jamaican secondary/high school in St. James Jamaica [80]. This study, on the other hand, was conducted in Kingston and St. Andrew and the results supports what obtained in the other end of the island. The reality is; teachers are utilizing soft strategies in classroom management in Jamaica which is equally the case around the globe. The soft strategy is a soft approach in managing students' behavioural problems as a part of effective classroom management.

Reynolds $[20,21]$ view disciplinary strategy as coercive, one in which the teachers use [harsh] measures such as overreliance on punishment to manage their class-hard strategies, which is different from the soft strategies that are more nurturing and positive in nature. Studies have established that students respond more favorably when the teacher provides more guidance instead of being more permissive $[27,68]$ and this may be among the explanations for poor under performance of students in the Jamaican educational system. Marzano, et al.'s work highlights the fact that there is a relationship between the employment of a

Table 5: Descriptive statistics on the employment of hard and soft strategies by gender.

\begin{tabular}{|l|l|l|}
\hline Details & Descriptive statistics & t-test statistic \& $\boldsymbol{P}$ value \\
\hline Hard strategies & & \\
\hline Male & $36.5 \pm 7.1 ; 34.0-39.0$ & $-1.510, P=0.143$ \\
\hline Female & $39.9 \pm 7.5 ; 35.8-44.1$ & \\
\hline Soft strategies & & \\
\hline Male & $84.7 \pm 12.0 ; 80.5-89.0$ & $-0.912, P=0.371$ \\
\hline Female & $88.6 \pm 14.3 ; 80.6-96.5$ & \\
\hline
\end{tabular}

particular strategies and academic performance [27]. But the question that must be answered is "Are teachers employing both hard and soft strategies simultaneously?" This is put forward and examined in research question 3.

Research question $\mathbf{2}$ was designed to investigate if the employment of hard and soft-strategies by teachers in their classroom differ based on socio-demographic characteristics. Socio-demographic characteristics refer to teachers: agegroup, gender, educational level, years of teaching experience, level of school taught by teachers and choice of shifting to another profession. A univariate analysis showed that there is no statistical difference with a $(P<0.05)$ who employed hard strategies. This means that whether an individual is a male or female-teacher, he/she employs hard strategies and this is the same based on one's age, educational level, teaching experience etc. For soft strategy, the univariate analysis showed no statistical difference in the selected variable of socio-demographic characteristics ( $F=1.445, P=0.204)$. This means that irrespective of the general socio-demographic differences, teachers are employing soft-strategies to effect better classroom management. It follows, therefore, that teachers are nurturing students psychologically and that the teaching-learning process include humanistic skills.

The sampled respondents of forty-eight (48) teacher measured the variable gender; $(68.8 \%)$ represented males and $(31.2 \%)$ being females; though the findings revealed a higher percentage of male than females in the sample. Using Independent sample t-test, there is no statistical difference between the employment of hard strategies by gender of respondents $(P=0.143)$, which is also the case for the employment of soft strategies $(P=0.371)$. This means that there is no gender disparity in the utilization of hard or soft strategies by teachers.

Research by Glasgow and Hicks [51] showed that female teachers than their male counterparts were more effective in the classroom. This can be attributed to the biological make-up of the female teacher, who is normally dubbed as nurturers. The issue of effectiveness in the classroom cannot be solely measured based on employment of soft or hard strategies in a classroom as academic performance needs

Table 6: Analysis of Variance (ANOVA) of employment of self-perceived hard and soft strategies by age of respondents.

\begin{tabular}{|c|c|c|c|c|c|}
\hline \multicolumn{2}{|c|}{ Strategies Age group } & \multirow{3}{*}{$\begin{array}{l}\mathbf{N} \\
14\end{array}$} & \multirow{3}{*}{\begin{tabular}{|l|} 
Mean \pm SD \\
$37.6 \pm 7.6$
\end{tabular}} & \multirow{3}{*}{\begin{tabular}{|l|}
$95 \% \mathrm{Cl}$ \\
Lower - Upper \\
$33.3-42.0$ \\
\end{tabular}} & \multirow{4}{*}{$\begin{array}{l}\text { F statistic \& } \boldsymbol{P} \text { value } \\
2.07 \& 0.117\end{array}$} \\
\hline \multirow{6}{*}{ Hard strategies } & & & & & \\
\hline & $\leq 30$ years & & & & \\
\hline & $31-40$ years & 23 & $36.2 \pm 7.1$ & $33.2-39.3$ & \\
\hline & $41-60$ years & 9 & $38.3 \pm 6.5$ & $33.4-43.3$ & \\
\hline & $50+$ years & 2 & $49.0 \pm 1.4$ & $36.3-61.7$ & \\
\hline & Total & 48 & $37.6 \pm 7.3$ & 35.4-39.7 & \\
\hline \multirow[t]{5}{*}{ Soft strategies } & $\leq 30$ years & 14 & $82.3 \pm 17.1$ & $72.3-92.2$ & \multirow{5}{*}{$1.504 \& 0.227$} \\
\hline & $31-40$ years & 23 & $87.8 \pm 10.0$ & $83.5-92.2$ & \\
\hline & $41-60$ years & 9 & $83.7 \pm 10.6$ & $75.5-91.8$ & \\
\hline & $50+$ years & 2 & $100.0 \pm 2.8$ & $74.6-125.4$ & \\
\hline & Total & 48 & $85.9 \pm 12.8$ & $82.2-89.6$ & \\
\hline
\end{tabular}


Citation: Brown MA, Bourne PA, Peterkin VMS (2019) An Empirical Assessment of Soft and Hard Classroom Management Strategies Employed by Teachers in Secondary Schools in Kingston and St. Andrew, Jamaica. Insights Anthropol 3(1):159-178

to be taken into consideration. Notwithstanding this fact, this research has revealed that Jamaica male teachers have a nurturing side to them as their female counterparts, and that there is no difference in employing hard or soft strategies based on gender. It can be deduced from the current findings that Jamaican teachers are caring, which is not only central to understanding the needs of students, it is also important in understanding the responses of teachers to students [22].

\section{Teacher's age group}

Table 5 presents descriptive statistics from the analysis of variance of the employment of hard and soft strategies by age cohort of the respondents. The ANOVA analysis revealed that employment of hard and soft strategies by Jamaican teachers do not vary based on the age of the teacher $(P>$ 0.05). On reviewing of the literature no study was found that examined this issue and so the current study provides new information that can be used to evaluate future issues.

\section{Teacher's education}

Table 6 presents an analysis of variance examination of the employment of self-perceived hard and soft strategies by educational level of respondents. It was revealed from the analysis that the employment of hard and soft strategies by Jamaican teachers does not statistically differ based on the educational level of the respondents (i.e., $P>0.05$ ). The issue of no statistical difference existing in the utilization of hard and soft strategies by Jamaican teachers based on their educational level indicates that there is something outside of one's educational attainment that accounts for employment of hard or soft skills in classroom by teachers.

Goldhaber [57] and Wenglinsky [81] found that two main attributes of teacher's quality (classroom management) which research state have been in conflict are teacher's educational level and teacher's experience. The current work disagrees with the aforementioned finding.

Table 7 presents descriptive statistics from an analysis of variance of employment of self-perceived hard and soft strategies by teaching experience from a sample of teachers. The findings revealed that no statistical difference existed among the years of teaching experience as it relates to the employment of hard strategies $(P<0.05)$, which is not the case for self-perceived soft strategies $(P>0.05)$. Further analysis of the findings indicates that teachers who have spent in excess of $20+$ years were more likely to employ hard strategies than

Table 7: Analysis of Variance (ANOVA) of employment of self-perceived hard and soft strategies by educational level.

\begin{tabular}{|c|c|c|c|c|c|}
\hline \multicolumn{2}{|c|}{ Strategies Educational level } & \multirow[t]{2}{*}{$\mathbf{N}$} & \multirow[t]{2}{*}{ Mean \pm SD } & \multirow{2}{*}{$\begin{array}{l}\text { 95\% Cl } \\
\text { Lower - Upper }\end{array}$} & \multirow[t]{2}{*}{ F statistic $\& P$ value } \\
\hline & & & & & \\
\hline \multirow[t]{4}{*}{ Hard strategies } & Certificate & 5 & $33.0 \pm 6.2$ & $25.3-40.7$ & \multirow{4}{*}{$1.392 \& 0.259$} \\
\hline & First degree & 30 & $38.6 \pm 6.8$ & 36.1-41.2 & \\
\hline & Graduate degree & 13 & $36.8 \pm 8.4$ & $31.8-41.9$ & \\
\hline & Total & 48 & $37.6 \pm 7.3$ & $35.4-39.7$ & \\
\hline \multirow[t]{4}{*}{ Soft strategies } & Certificate & 5 & $81.8 \pm 1.1$ & $80.4-83.2$ & \multirow{4}{*}{$0.998 \& 0.377$} \\
\hline & First degree & 30 & $84.9 \pm 14.5$ & 79.4-90.4 & \\
\hline & Graduate degree & 13 & $89.9 \pm 8.7$ & $84.7-95.2$ & \\
\hline & Total & 48 & $85.9 \pm 6$ & $82.2-89.6$ & \\
\hline
\end{tabular}

Table 8: Analysis of Variance (ANOVA) of employment of self-perceived hard and soft strategies by teaching experience.

\begin{tabular}{|c|c|c|c|c|c|}
\hline \multicolumn{2}{|c|}{ Strategies Teaching experience } & \multirow{3}{*}{\begin{tabular}{|l|}
$\mathbf{N}$ \\
13
\end{tabular}} & \multirow{3}{*}{\begin{tabular}{|l} 
Mean \pm SD \\
$36.8 \pm 8.1$ \\
\end{tabular}} & \multirow{2}{*}{$\begin{array}{l}\mathbf{9 5 \%} \mathbf{C l} \\
\text { Lower - Upper }\end{array}$} & \multirow[t]{2}{*}{ F statistic $\& P$ value } \\
\hline & & & & & \\
\hline \multirow[t]{6}{*}{ Hard strategies } & $\leq 5$ years & & & $31.9-41.6$ & \multirow{6}{*}{$3.136 \& 0.035$} \\
\hline & & & & & \\
\hline & $6-10$ years & 12 & $40.8 \pm 5.2$ & $37.5-44.0$ & \\
\hline & $11-20$ years & 17 & $34.3 \pm 6.7$ & $30.8-37.7$ & \\
\hline & $20+$ years & 6 & $42.2 \pm 7.2$ & $34.6-49.7$ & \\
\hline & Total & 48 & $37.6 \pm 7.3$ & $35.4-39.7$ & \\
\hline \multirow[t]{5}{*}{ Soft strategies } & $\leq 5$ years & 13 & $81.4 \pm 17.1$ & $71.0-91.7$ & \multirow[b]{2}{*}{$0.904 \& 0.447$} \\
\hline & $6-10$ years & 12 & $88.7 \pm 10.5$ & $82.0-95.3$ & \\
\hline & $11-20$ years & 17 & $88.0 \pm 9.2$ & 83.3-92.7 & \\
\hline & $20+$ years & 6 & $84.5 \pm 14.9$ & $68.9-100.1$ & \\
\hline & Total & 48 & $85.9 \pm 12.8$ & $82.2-89.6$ & \\
\hline
\end{tabular}


Citation: Brown MA, Bourne PA, Peterkin VMS (2019) An Empirical Assessment of Soft and Hard Classroom Management Strategies Employed by Teachers in Secondary Schools in Kingston and St. Andrew, Jamaica. Insights Anthropol 3(1):159-178

their less experienced counterparts.

The fact that teachers with more years of experience were more likely to utilize hard strategies in their class compared to their less experienced counterparts goes to the crux of the matter, which is the difficulty of changing practices by people. Traditional teachers would have been exposed or taught less soft skills in the management of their classroom, which explains what obtains in the current work. The reality is, long serving teachers would have been exposed to traditional best practices that have radically change in the last 10 years. Best practices are available practices that are tried and proven consistently to be effective and are supported from the literature [82]. Simply put, they include 1) Conceptualization and operational definitions, 2) Question on effectiveness, 3) Philosophical framework, and 4) Levels of teaching practices. While the more experience teachers have used more traditional teaching practices, knowledge and understanding of pedagogy, their less experienced counterparts have been introduced to new practices, techniques, and knowledge that did not exist when the more experienced teachers would have been trained. Teaching method such as cooperative learning is a relatively new approach in teaching and did not exist when many of the traditional teachers would have been trained.

Nevertheless, studies have found that teachers with more years of teaching experience were no more effective than those with fewer years of teaching experience $[53,55]$. On the contrary, Zhang [59] believed that teachers having more years of experience teaching one particular subject will have a greater impact on student achievement in that subject than those teachers who have fewer years teaching that subject. The researchers [57,81] found that in some cases there is a high positive relationship while in other cases there is no relationship between years of teaching experience and students' academic achievement. On the other hand, a positive relationship occurs where teacher's quality and teacher's experience have a great impact on students' achievement [58]. On the other side, that is where there is no relationship a possibility could relate to other factors, such as disruptive students, economic disturbances, a culture of school or community violence, and teacherstudent relationship. These factors could also relate to what is happening in the schools in Kingston and St. Andrew in terms of proper use of strategy yet not much positive results are seen in classroom management in some schools.

Regardless of the benefits to be derived from teacher's seeing their students achieve to optimal levels; it was alarming to note that $66.7 \%$ of the said teachers indicated that they would choose another profession, if they had the opportunity. This could be resulting from the teacher's stress of having to deal with some disruptive students which do impact teacher's performance and their attitude towards the students which are all important in effective classroom management [36].

Research question 3: Is there a correlation between the employment of hard and soft strategies by Jamaican teachers in their classroom?

The answer to the dual employment of hard and soft strategies is answered by this research. This study found that there is no correlation between the employment of hard and soft strategies by Jamaican teachers in their classroom (Table 8).

A correlation was done between self-perceived hard and self-perceived soft strategies employed by respondents, which is presented in Table 9. No significant statistical correlation existed between both variables, which means that the sampled respondents (or teachers) do not simultaneously employed both hard and soft strategies in their classroom. It follows; therefore, that teacher will employ either hard or soft strategies in their classroom.

It can be deduced from the findings in Table 8 that Jamaican educators at the secondary level singly employ a hard or soft strategy and that they are not twinned in classroom management. An extensive review of the literature did not unearth a single study that speaks to this matter, which is new ground examined by this work.

Pedota [17], posited that before the teaching process

Table 9: Correlation of self-perceived hard strategies and selfperceived hard strategies employed by teachers in classroom.

\begin{tabular}{|l|l|l|l|}
\hline \multicolumn{2}{|l|}{} & $\begin{array}{l}\text { Hard } \\
\text { Strategies }\end{array}$ & $\begin{array}{l}\text { Soft } \\
\text { Strategies }\end{array}$ \\
\hline \multirow{3}{*}{ Hard Strategies } & Pearson Correlation & 1 & 0.002 \\
\cline { 2 - 4 } & Sig. (2-tailed) & & 0.988 \\
\cline { 2 - 4 } & N & 48 & 48 \\
\hline \multirow{3}{*}{ Soft Strategies } & Pearson Correlation & 0.002 & 1 \\
\cline { 2 - 4 } & Sig. (2-tailed) & 0.988 & \\
\cline { 2 - 4 } & N & 48 & 48 \\
\hline & & & \\
\hline
\end{tabular}

Table 10: Analysis of Variance (ANOVA) of employment of self-perceived hard strategies by who is responsible for instituting strategies in the classroom.

\begin{tabular}{|l|l|l|l|l|}
\hline $\begin{array}{l}\text { Responsible for } \\
\text { Employing strategies }\end{array}$ & N & Mean SD & 95\% Confidence Interval & F statistic \& P value \\
\hline Dean \& principal & 15 & $39.4 \pm 7.5$ & Lower - Upper & \\
\hline Parents & 2 & $30.0 \pm 10.0$ & $35.3-43.5$ & $2.345 \& 0.086$ \\
\hline Form teachers & 25 & $38.3 \pm 6.7$ & $-58.9-118.9$ & \\
\hline Subject teachers & 6 & $32.3 \pm 6.0$ & $35.5-41.1$ & \\
\hline Total & $\mathbf{4 8}$ & $\mathbf{3 7 . 6} \pm \mathbf{7 . 3}$ & $\mathbf{2 6 . 0 - 3 8 . 7}$ & \\
\hline
\end{tabular}


Citation: Brown MA, Bourne PA, Peterkin VMS (2019) An Empirical Assessment of Soft and Hard Classroom Management Strategies Employed by Teachers in Secondary Schools in Kingston and St. Andrew, Jamaica. Insights Anthropol 3(1):159-178

begins, adequate time must be spent devoted to preparation, and developing procedures, that will inevitably maximize instruction and enhance learning in a climate that is positive.

Research question 4: Does the employment of hard and soft-strategies by teachers in their classroom differ based on who is responsible for the employment of the strategies in the classroom, introduction of school rules to new students in the class, who normally reminds the students of the rules?

Table 10 is a presentation of the analysis of variance of the employment of self-perceived hard strategies by who is responsible for instituting these in the classroom. The findings show that whether it is the Dean of discipline and the Principal, parents, form teachers or the subject teachers, there is no statistical difference with the employment of hard strategies by a classroom teacher $(F=2.345, P>0.05)$. This means that the responsibility of an educator or other agents of the educational system as well as parents do not matter in the utilization of hard strategies in the classroom, suggesting that classroom teachers are mini-gods or operating in a class as untouchables.

According to Green and Henriquez-Green [82], there are three basic moves of teaching. They are as follows: 1) Knowing how to establish a healthy, productive learning environment; 2) Having the knowledge and skill to set up an environment to ensure interaction, which includes being able to ask meaningful questions, and 3) Knowing how to use assessment to ensure that learning has taken place. These issues account for employment of different strategies to deal with classroom management in secondary schools in Jamaica. The reality is, Jamaican educators continue to utilize hard and soft strategies to manage their classrooms, and that selected demographic characteristics such as educational level, gender, and age do not influence how these strategies are used.

\section{Recommendations}

1. The Ministry of Education should do quarterly audits of schools, particularly as it relates to disruptive students, classroom management and review policies yearly in keeping with cultural and global changes.

2. Schools should ensure that new and present teachers are continuously equipped through training in the use of various strategies to manage an effective classroom.

3. The Ministry of Education should seek funding from UNICEF to conduct training on strategies suitable for effective classroom management from the primary to the university level. This should be done in order to fulfill the mandate in the Millennium Development Goal, which is an objective of the government.

4. Schools should encourage teachers to report disruptive students and should work along with psychologist, psychiatrist and medical clinics to offer suitable intervention if and when necessary.

5. Teachers' should utilize a caring attitude or soft strategy than "hard" disciplinary strategy to address disruptive students as it could enhance their academic achievement and create a change in behavior.

6. Teachers should use combined strategies (Soft and Hard) when dealing with very difficult children who have a history of violent behavior.

7. Teachers should improve parent-teacher relationship in order to better aid students in their holistic development.

8. The replication of this study is suggested to be administered in other parishes in Jamaica to determine if results found in this study are similar and consistent island wide.

9. It would be interesting to pursue this topic as an intervention study measuring the same constructs and including performance.

10. Questionnaire should be reviewed to capture respond from students on how the different strategies impacted them. It would make the research stronger.

11. More research should be conducted on socio-demographic characteristics of teachers as it relates to soft and hard strategies and its effect on classroom management.

\section{Recommendations for Further Research}

This study supplement research associated to evaluate classroom management strategies employed by teachers in twenty secondary (or high) schools in Kingston and St Andrew. No one study can sufficiently explore and investigate all aspects of this topic, hence recommendations for future research include the following:

1. Researchers could expand the study and include a larger sample and population which includes other schools from different regions in Jamaica.

2. The researchers could include how these hard or soft strategies impact students' learning or achievements.

\section{Implications}

This study was carried out in twenty (20) secondary schools in Kingston and St Andrew evaluating the classroom management strategies employed by teachers to find out if effective classroom management strategies depends more on the teacher's caring attitude (soft strategies) than "hard" disciplinary strategies. The results of this study showed that Jamaican teachers continue to employ both soft and hard strategies in their classroom. It also revealed that soft strategies are used marginally used more than the hard strategies among the teachers.

The present study may assist stakeholders in the educational process. As our society is moving towards enhancing student achievement and improving behavior across all grade levels, classroom management needs to be considered. It was very evident that teachers are aware of what constitutes an effective classroom setting but however due to the high level of indiscipline they choose to use the strategies that will work for them best in a given situation. It may also have implications for teacher induction, retention and development programs for staff. Another implication is that educators could also be provided with a better understanding of some of the challenges that teachers are faced with on a daily basis when 
Citation: Brown MA, Bourne PA, Peterkin VMS (2019) An Empirical Assessment of Soft and Hard Classroom Management Strategies Employed by Teachers in Secondary Schools in Kingston and St. Andrew, Jamaica. Insights Anthropol 3(1):159-178

interacting or teaching students during the teaching learning environment. Another implication is that administrators should seek to improve their school's indiscipline by listening to teachers and use their feedback in implementing policies that will positively affect how they carry out their jobs in molding the nation's future leaders.

\section{Conclusion}

The art of good classroom management is one of the most important goal teachers try to achieve and must strive to establish from the very first day of class. Students must be cognizant of the procedures, rules, activities, and behaviors that are required and thus set the tone throughout the school year. Thus a caring attitude or soft and "hard" disciplinary strategies must be employed for effective classroom management. The type of strategy teacher employ will be dependent on the student's behavior and situation at any given time. Teacher's must also ensure that their psychosocial system is balanced to endure the stress of dealing with various student's personality type. There is no hard and fast way to solve the problems of teacher-student relationships, the culture of school violence and student-student relationships application of the best strategy that will bring about a more effective classroom. A lack of classroom management affects both students and the teacher to a point that causes teachers to leave the profession all together. "Early attention to classroom management at the beginning of the school year is a critical ingredient of a well-run classroom" [7].

Early studies have shown that if inexperienced teachers are able to prepare for classroom management struggles by taking courses about classroom management, they were better prepared for life in the real classroom [83]. By letting students know what behavior is expected of them at any given point in time, and adding variety and challenge in the seatwork assigned to students is prescribed because students need choice and a challenge, this would reduce the probability of employing hard strategies. Students will get bored with monotonous seat work if it is not chosen for specific purpose and with differentiation in mind.

Controversies in classroom management strategies stem from the duel between behaviorist and social constructivist points of view. Behaviorists tend to focus attention on the individual student, whereas social constructivists tend to focus their attention on the whole group and what is the best fit for the entire group [83].

There are many aspects of classroom management for teachers to consider and think about, especially in their first few years of teaching. The most important thing for teachers to remember is the reason they chose to teach in the first place. Classroom management skills do not develop overnight; a teacher should have routines set up in the classroom and stick by those routines throughout the year. Again, take a deep breath and remember the reasons for becoming a teacher.

\section{References}

1. Boynton C, Boynton M (2005) The education's guide to preventing and solving discipline problems. The association for supervision and curriculum development (ASCD), USA.

2. Braden S, Smith D (2006) Managing the college classroom: Perspectives from an introvert and an extrovert. College Quarterly 9: 1-9.

3. Rogers C, Freiberg J (1994) Freedom to learn. ( $3^{\text {rd }}$ edn), Merrill Publishing, Upper Saddle River, USA.

4. Etheridge $T$ (2010) Assertive discipline and its impact on disruptive behaviour. Dissertation completed at Capella University, 1-118.

5. Canter L (2006) Classroom management for academic success. Solution Tree, Bloomington, Indiana.

6. Daly T (2005) How to turn any disruptive child into your best student? ( $2^{\text {nd }}$ edn), Smarty Pants Publications, LaJolla, California.

7. Marzano R (2003) What works in schools: Translating research into action? ASCD Publications, Virginia.

8. Sulich M (2004) "Keeping discipline in the classroom": English Teaching Forum 42/3 Lunenburg. In: FC, Irby BJ, Writing a successful thesis or dissertation. Corwin Press, Thousand Oaks, California.

9. Brown D (1994) Teaching by principles. Prentice Hall Regents.

10. Martin NK, Baldwin B (1995) Beliefs regarding classroom management style: Differences between novice and experienced teachers. A paper.

11. Lassonde CA, Lassonde (2010) Classroom management. In: C presented to the American Educational Research Association Conference, San Francisco. Kridel, Encyclopedia of curriculum studies. Sage Publications, Thousand Oaks, California.

12. Wolfgang CH (1995) Solving discipline problems: Strategies for classroom teachers. ( $3^{\text {rd }}$ edn), Allyn and Bacon, Boston.

13. Lemlech JK (1988) Classroom management: Methods and techniques for elementary and secondary teachers. ( $\left.2^{\text {nd }} e d n\right)$, Longman, New York.

14. Smith CJ, Laslett R (1993) Effective classroom management: A teacher's guide. ( $2^{\text {nd }}$ edn), Routledge, New York.

15. Ogunu M (2000) Introduction to educational management. Mabogun Publishers, Benin City.

16. McDaniel SC, Yarbrough AM, Ruma KV (2014) Coaching to improve classroom management. Principal leadership, 14: 36-41.

17. Pedota $P$ (2007) Strategies for effective classroom management in the secondary setting. The clearing house, 80: 163-166.

18. Pocket Power Guide (2013) Soft skills: Be professionally proactive. $\left(2^{\text {nd }} \mathrm{edn}\right)$, lland Business Pages.

19. Eyster RH, Martin C (2010) Successful classroom management: Real-world, time-tested techniques for the most important skills set every teacher needs. Sourcebooks, Illinois.

20. Reynolds TJ (1985) “Implications for Value Research: A Micro vs. Macro Perspective". Psychology and Marketing 2: 297-305.

21. Ayers H, Gray F (2012) Classroom management: A practical approach for primary and secondary teacher. Taylor and Francis Routledge, London.

22. Ackerly SS, Bernstein L, Erwin E, et al. (1960) Fostering mental health in the classroom. Journal of Teacher Education.

23. Arbuckle C, Little E (2004) Teachers' perceptions and management of disruptive classroom behaviour during the middle years (years five to nine). Australian Journal of Educational \& Developmental Psychology 4: 59-70. 
Citation: Brown MA, Bourne PA, Peterkin VMS (2019) An Empirical Assessment of Soft and Hard Classroom Management Strategies Employed by Teachers in Secondary Schools in Kingston and St. Andrew, Jamaica. Insights Anthropol 3(1):159-178

24. Vitto J (2003) Relationship-Driven classroom management: Strategies that promote student motivation. Corwin Press Inc. A Sage Publication Company. Thousand Oaks, California.

25. Williams P, Sullivan S, Kohn L (2012) Out of the mouths of babes: What do secondary students believe about outstanding teachers? American Secondary Education, 40: 104-119.

26. Talbott J (2005) The relationship between observable teaching effectiveness behaviors and personality types in a sample of urban middle school teachers (Doctoral dissertation). Retrieved from ProQuest Dissertations and Theses database.

27. Walker JMT (2009) Authoritative classroom management: How control and nurturance work together. Journal of Experimental Education 76: 218-240.

28. Elliott J (1994) Research on teachers' knowledge and action research. Educational Action Research 2: 133-137.

29. Good T, Brophy J (1987) Looking in classroom. $\left(4^{\text {th }}\right.$ edn), Harper \& Row, New York.

30. Martin NK, Sass D (2010) Construct validation of the behavior and instructional management scale. Teacher and Teacher Education. University of Texas, San Antonio.

31. Research for teachers (2008) Carl rogers and classroom climate.

32. Ganly S (2010) BF Skinner's Theories on Discipline in the Classroom.

33. Charles CM, Senter GW (2004) Building classroom discipline. ( $8^{\text {th }}$ edn), Allyn \& Bacon, Boston, Massachusetts.

34. Kounin JS (1970) Discipline and group management on classrooms. Holt, Rinchart \& Winston, New York.

35. Echelberge E (1959) Relationships between Personality Traits and Peer Status. Unpublished doctoral dissertation. The University of Michigan.

36. Stringer LA (1959) Academic progress as an index of mental health. Journal of Social Issues 15: 16-29.

37. Kane TJ, Taylor ES, Tyler JH, et al. (2011) Identifying effective classroom practices using student achievement data. Journal of Human Resources 46: 587-613.

38. Wong HK, Wong RT (2005) How to be an effective teacher: The first days of school. Harry K Wong Publication, Inc, California.

39. Skinner BF (1950) Are theories of learning necessary? The Psychological Review 57: 193-216.

40. Sowell HK (2013) Classroom management strategies: The impact on student achievement.

41. Andrius J (2012) The jones model of discipline. Teacher Matters.

42. Skinner BF (1974) About behaviorism. Random House, New York.

43. McLeod SA (2015) Skinner- operant conditioning.

44. Skinner BF (1948) Superstition in the pigeon. Journal of Experimental Psychology 38: 168-172.

45. Bandura A (1977) Social learning theory. Prentice Hall, Englewood Cliffs, USA.

46. Bandura A (1986) Social foundations of thought and action: A social cognitive theory. Prentice-Hall, New Jersey.

47. Bandura A (1997) Self-efficacy: The exercise of control. New York.

48. Bandura A (2001) Social cognitive theory: An agentic perspective. Annual Review of Psychology 52: 1-26.
49. Bower GH (1975) Cognitive psychology: An introduction. In: WK Estes, Handbook of learning and cognition. Erlbaum Associates, New Jersey, 25-80.

50. Neisser U (1976) Cognition and Reality: Principles and Implications of Cognitive Psychology. WH Freeman and Company, New York.

51. Glasgow N, Hicks C (2003) What successful teachers do researchbased classroom strategies for new and veteran teacher. A Sage Publications Company. Thousand Oaks, California, USA.

52. Evans K (2016) The role of teacher: Teacher insight scores and teacher demographic characteristics in the identification of effective teachers: Using student performance as a validation tool. Doctor of education in educational leadership: University of Missouri, USA.

53. Goldhaber DD, Brewer DJ (1996) Why don't schools and teachers seem to matter? Assessing the impact of unobservables on educational productivity. Revised version of a paper presented at meetings of the Econometric Society, San Francisco, California.

54. Goldhaber DD, Brewer DJ (2000) Does teacher certification matter? High school teacher certification status and student achievement. Educational Evaluation and Policy Analysis 22: 129-145.

55. Ye RM (2000) The effect of teacher characteristics, beliefs, relations with students, and in-service education on student science achievement. Unpublished doctoral dissertation, Texas Technology University.

56. Hawkins EF, Stancavage FB, Dossey JA (1998) School policies and practices affecting instruction in mathematics (NCES 98-495). National Center for Education Statistics, Washington, USA.

57. Goldhaber DE (2004) Indicators of teacher quality. ERIC Clearing house on Urban Education New York NY.

58. Greenberg E, Rhodes D, Ye X, et al. (2004) Prepared to teach: Teacher preparation and student achievement in eighth-grade mathematics.

59. Zhang D (2008) The effect of teacher education level, teaching experience, and teaching behaviors on student science achievement (Doctoral dissertation).

60. Hanushek EA (1997) Assessing the effects of school resources on student performance: An update. Educational Evaluation and Policy Analysis 19: 141-164.

61. Richardson AF (2008) An examination of teacher qualifications and student achievement in mathematics (Doctoral dissertation).

62. Murnane RJ (1975) The impact of school resources on the learning of inner city children. Ballinger, Cambridge.

63. Rivkin SG, Hanushek EA, Kain JF (2005) Teachers, schools, and academic achievement. Econometrica 73: 417-458.

64. Rockoff JE (2004) The impact of individual teachers on student achievement: Evidence from panel data. American Economic Review 94: 247-252.

65. Stein L (2010) Lead students -- Don't just manage them. Phi Delta Kappan 91: 82-86.

66. Koh S (2008) Leadership and management skills of pre-service teachers (Doctoral Dissertation).

67. Mitchell MM, Bradshaw CP (2013) Examining classroom influences on student perceptions of school climate: The role of classroom management and exclusionary discipline strategies. $J$ Sch Psychol 51: 599-610. 
Citation: Brown MA, Bourne PA, Peterkin VMS (2019) An Empirical Assessment of Soft and Hard Classroom Management Strategies Employed by Teachers in Secondary Schools in Kingston and St. Andrew, Jamaica. Insights Anthropol 3(1):159-178

68. Marzano R, Marzano L, Pickering D (2003) Classroom management that works: Research-based strategies for every teacher. Association for supervision and curriculum development, Alexandria, USA.

69. Rischer A (2008) Management strategies help to promote student achievement. Education Digest 74: 47-49.

70. Creswell JW (2013) Qualitative inquiry and research design: Choosing among five approaches. Sage Publications, Thousand Oaks, California.

71. Berg B (2001) Qualitative Research Methods for the social sciences. ( $4^{\text {th }}$ edn), Allyn and Beacon, USA.

72. Goel M (1988) Political science research: A methods handbook. lowa State University Press, USA.

73. Babbie E (2007) The Practice of Social Research. $\left(10^{\text {th }}\right.$ edn), Wadsworth, a Division of Thomson Learning, Inc.

74. Leedy P, Ormrod J (2010) Practical Research Planning and Design. ( $9^{\text {th }}$ edn), Pearson Educational Inc, USA.

75. Creswell JW (2008) Educational research Planning, conducting, and evaluating quantitative and qualitative research. ( $3^{\text {rd }} \mathrm{edn}$ ), Upper Saddle River, New Jersey.

76. Crotty M (2005) The foundations of social research: Meaning and perspective in the research process. SAGE, London.

77. Strauss A, Corbin J (1998) Basics of qualitative research techniques and procedures for developing grounded theory. Sage, Los Angeles.

78. Neuman WL (2006) Social research methods: Qualitative and quantitative approaches. ( $6^{\text {th }}$ edn), Pearson/Allyn and Bacon, New York.

79. Blasé J (1986) Qualitative analysis of sources of teacher stress: Consequences for performance. American Educational Research Journal 23: 13-40.

80. Sacco FC, Twemlow SW (1997) School violence reduction: A model Jamaican secondary school program. Community Mental Health J 33: 229.

81. Wenglinsky H (2002) The link between teacher classroom practices and student academic performance. Education Policy Analysis Archives 10.

82. Green HW, Henriquez-Green R (2008) Basic moves of teaching: building on cooperative learning. Trafford Publishing, Canada.

83. Arends R (1997) Classroom Teaching: A Demanding Job in a Complex Setting. In Classroom Instruction and Management. McGraw-Hill, New York, 15-61. 